\title{
An Unusual Case Report Of Hepatocellular Carcinoma Metastasis To The Chest Wall Presenting As Breast Lump
}

\author{
Ahmad K, ${ }^{1}$ Sah PL, ${ }^{1}$ Dhungel K, ${ }^{1}$ Gupta MK, ${ }^{1}$ Rauniyar RK, ${ }^{1}$ Ansari $S,{ }^{1 *}$ Paudyal $P^{2}$ \\ ${ }^{I}$ Department of Radiodiagnosis, B.P. Koirala Institute of Health Sciences, Dharan, Nepal, ${ }^{2}$ Department of Pathology, B.P. \\ Koirala Institute of Health Sciences, Dharan, Nepal.
}

\begin{abstract}
* Corresponding Author:
Dr. Sajid Ansari,

Resident, Department of Radiodiagnosis,

B.P. Koirala Institute of Health Sciences, Dharan, Nepal.

Address - H-27-33. BPKIHS, Dharan, Nepal

Email address: drsajidansari@yahoo.co.in

\section{Citation}

Ahmad K, Sah PL, Dhungel K, Gupta MK, Rauniyar RK, Ansari S, Paudyal P. An unusual case report of hepatocellular carcinoma metastasis to the chest wall presenting as breast lump. Nepal Journal of Medical sciences 2012;1(2):138-40.
\end{abstract}

\begin{abstract}
Hepatocellular carcinoma (HCC) is the most frequent primary malignant tumor of the liver. Chronic hepatitis B infection is the most common cause of HCC. Bony metastasis of HCC is usually rare, in which the most common sites involved are vertebra, pelvis, rib and skull. Still rarer are metastasis to the chest wall. Metastatic HCC has an aggressive course and poor prognosis. Hereby, we report an unusual case of HCC metastasis which presented initially as swelling of the anterolateral aspect of the chest wall.
\end{abstract}

Keywords: Hepatocellular carcinoma; metastases; chest wall

\section{Introduction:}

Hepatocellular carcinoma (HCC) is the most frequent primary malignant tumor of the liver. ${ }^{1}$ It is usually seen in sixth and seventh decades of life in the western world, whereas in Asia and Africa, it usually occurs in the fourth decade of life. It is found more commonly in the males. ${ }^{2}$ Chronic hepatitis B infection has been defined as the most common etiologic factor. ${ }^{1}$ Hematogeneous extrahepatic metastases are common, with lungs, regional lymph nodes, kidneys, bone marrow and adrenals being the most frequent sites. ${ }^{3}$ Metastasis of HCC to bones is usually rare, in which the most common sites involved are vertebrae and pelvis. Metastases to the chest wall have rarely been reported before.

\section{Case report:}

A 75 year old male was referred for ultrasonography (USG) of chest with complaints of swelling in the left anterolateral chest region of 4 months duration. There was no history of pain over the swelling, jaundice, fever, night sweats or alcohol intake. His physical examination revealed a 9x8 cm, fixed, hard swelling in the left anterolateral region of the chest.

USG of the swelling in the left chest region revealed solid, heterogeneous mass predominantly echogenic with increased internal vascularity. USG abdomen revealed large, well defined, heterogeneous mass of size $13 \times 8.5 \mathrm{~cm}$ in the left lobe of liver. Total and direct bilirubin and liver enzymes were within normal limits. Viral marker profile was not reactive for both $\mathrm{HBsAg}$ and $\mathrm{HCV}$.

Chest radiograph demonstrated well defined mass in the left mid and lower zones with destruction of the left anterior $4^{\text {th }}$ rib. Computed tomography (CT) of the thorax (Figure 1) revealed soft tissue mass lesion in the left anterolateral aspect of the chest wall with intra and extrathoracic component 
along with destruction of the left anterior $4^{\text {th }}$ rib.

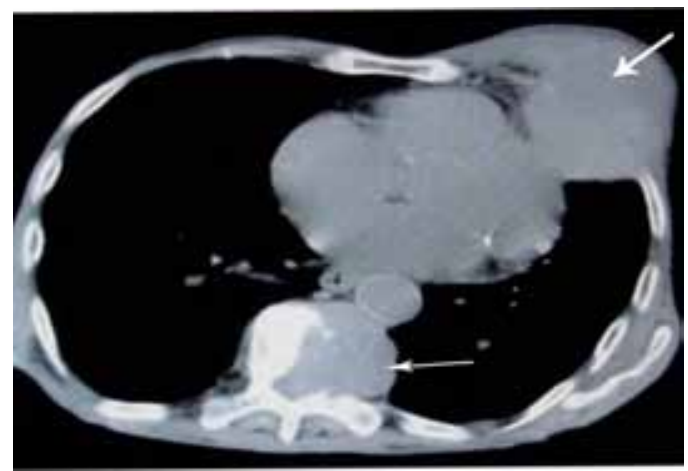

Figure 1: Axial CT scan of the chest showing mass in left anterolateral chest wall with intra \& extrathoracic component along with destruction of adjacent rib and vertebral destruction with soft tissue component

There was also destruction of $8^{\text {th }}, 9^{\text {th }} \& 10^{\text {th }}$ dorsal vertebrae along with soft tissue component causing compression of the spinal cord at the same level. Abdominal CT scan (Figure 2) revealed a $13 \times 8.5 \mathrm{~cm}$, well circumscribed, heterogeneous mass in the left lobe of the liver. There were no enlarged abdominal and chest lymph nodes.

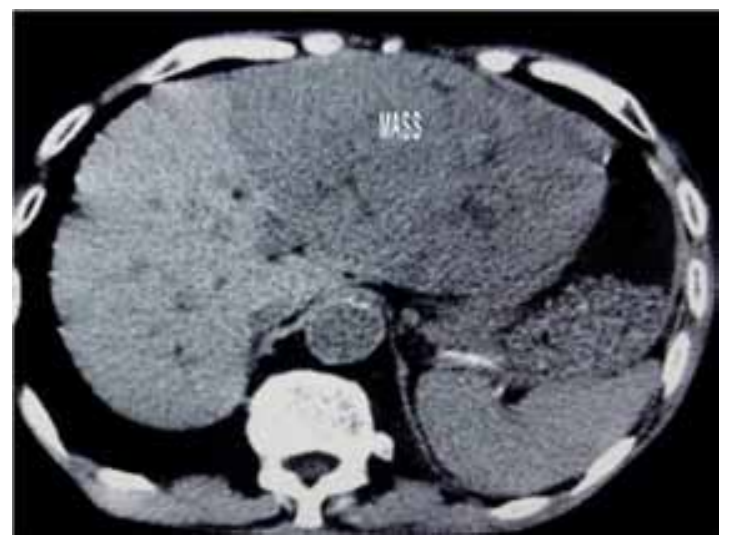

Figure 2: Axial CT scan of the abdomen showing a welldefined heterogeneous mass lesion in the left lobe of liver.

Cytological examination of a fine needle aspirate taken from the mass in the chest wall (figure 3 ) as well as in the liver was consistent with the diagnosis of HCC.

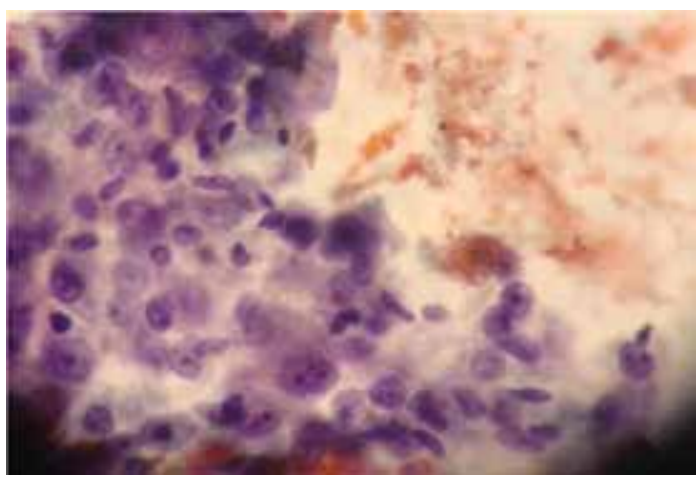

FIGURE 3: Cytological examination from the chest wall swelling shows malignant hepatocytes and traversing endothelial cells consistent with metastatic hepatocellular carcinoma (X 400 Papanicolaou stain).

\section{Discussion:}

Metastatic HCC has an aggressive course with a very poor outcome. ${ }^{4}$ The 5 -year survival in patients with symptomatic $\mathrm{HCC}$ being $0.8 \%$ in men and $4.4 \%$ in women. ${ }^{4}$ Hematogenous metastases is common, and the usual sites are lung (49\%), bone $(16 \%)$, adrenal glands $(15 \%)$, pancreas $(4 \%)$, kidney $(3 \%)$ and the spleen $(2 \%)$, as ascertained in an autopsy series. ${ }^{4}$ Metastasis of HCC occurs frequently through intrahepatic blood vessels, lymphatic permeation or direct infiltration. HCC metastases to bone are seen in $3.0-10.0 \%$ of HCC patients. ${ }^{5-10}$ The common sites are vertebra, pelvis, ribs and skull. ${ }^{11}$ The bony lesions due to metastatic HCC in our case was osteolytic. However, multiple osteolytic lesions simulating multiple myeloma can be due to metastatic HCC. ${ }^{12}$ The etiology of HCC is still unknown in this patient. Clinical, laboratory parameters or radiological features were not suggestive of chronic liver disease. HCC is usually been found to develop on a background of cirrhosis but can also originate in normal or non-cirrhotic hepatic parenchyma. Primary $\mathrm{HCC}$ in patients without cirrhosis occurs in $37.0 \%$ of South African black population. ${ }^{13}$ Aflatoxin B produced by aspergillus species can be one of the causes. A close correlation between the degree of fungal contamination and frequency of HCC has been reported in tropical areas like sub-Saharan Africa and South East Asia. ${ }^{14,15}$

Chronic hepatitis B infection has been defined as the most common etiologic factor for HCC. ${ }^{1}$ But in our case as the viral marker profile was not reactive for both $\mathrm{HBsAg}$ and $\mathrm{HCV}$, hence it excludes the possibility of chronic hepatitis $\mathrm{B}$ infection.

To diagnose metastatic HCC without an unknown primary is a great challenge. It can be explained as being either due to ectopic liver carcinogenesis or hepatoid adenocarcinoma. ${ }^{16,17}$ Hepatoid adenocarcinoma is a variant form of adenocarcinoma, characterized by vast hepatic differentiation that produces alpha-fetoprotein, while having the same function and form as HCC. ${ }^{16}$

In our case, primary HCC was confirmed by fine needle aspiration cytology and hence the presence of primary $\mathrm{HCC}$ and multiple metastases in chest wall and vertebrae excludes ectopic HCC.

\section{Conclusion:}

We conclude hereby that bony metastasis of HCC should be 
included in the differential diagnosis of lump in the chest wall even in the absence of chronic liver disease.

\section{References:}

1. Anthony P. Hepatocellular carcinoma: an overview. Histopathol 2001;39:109-18.

2. Bosch FX, Ribes J, Díaz M, et al. Primary liver cancer: worldwide incidence and trends. Gastroenterol 2004;127:s5-16.

3. Katyal S, Oliver JH, Peterson MS, et al. Extrahepatic metastasis of hepatocellular carcinoma. Radiol 2000;216:698-703.

4. Qureshi SS, Shrikhande SV, Borges AM, et al. Chest wall metastases from unknown primary hepatocellular carcinoma. J Postgrad Med 2005;51:41-2.

5. Si MS, Amersi F, Golish SR, et al. Prevalence of metastases in hepatocellular carcinoma: risk factors and impact on survival. Amer Surg 2003;69:879-85.

6. Doval DC, Rao RC, Acharya R, et al. Hepatocellular carcinoma metastatic to bones. Indian $\mathrm{J}$ Cancer $1995 ; 32: 31-5$

7. Edmondson HA, Stenier PE. Primary carcinoma of liver: a study of 100 cases among 48,900 necropsies. Cancer 1954;7:462-503.

8. Okuda K. Clinical aspects of Hepatocellular carcinoma: analysis of 134 cases. In Okuda K, Peters RL, ed: Hepatocellular carcinoma. New York: John Wiley \& Sons 1976; 387-436.

9. Liaw CC, Kim Thean NG, Chen TJ, et al. Hepatocellular carcinoma as bone metastasis. Cancer 1989;64:1753-7.
10. Okazaki N, Yoshino M, Yoshida T, et al. Bone metastasis in hepatocellular carcinoma. Cancer 1985;55:1991-4.

11. Fukutomi M, Yokota M, Chuman H, et al. Increased incidence of bone metastases in hepatocellular carcinoma. Eur J Gastroenterol Hepatol 2001;13:1083-8.

12. Doval DC, Bhatia K, Vaid AK, et al. Bone metastases from primary hepatocellular carcinoma. Hepatobiliary Pancreat Dis Int'1 2005;4:308-10.

13. Cushieri A. Disorders of the liver. In Cushieri A, Steele RJC, Moossa AR, ed: Essential surgical practice: higher surgical training in general surgery.4th ed. New York:Arnold 2002: 353.

14. Yu MC, Yuan JM. Environmental factors and risk for hepatocellular carcinoma. Gastroenterol 2004;127:s72-8.

15. Wogan GM. Dietary risk factors for primary hepatocellular carcinoma. Cancer Detect Prey 1989;14:209.

16. Hyun YS, Choi HS, Bae JH, et al. Chest wall metastasis from unknown primary site of hepatocellular carcinoma. World J Gastroenterol 2006;12:2139-42.

17. Arakawa M, Kimura Y, Sakata K, et al. Propensity of ectopic liver to hepatocarcinogenesis: Case reports and a review of the literature. Hepatology 1999;29:57-61. 